\title{
Cognitive Training for Very High Risk Incarcerated Adolescent Males
}

\begin{abstract}
Abby Rowlands ${ }^{1}$, Melissa Fisher ${ }^{2}$, Jyoti Mishra ${ }^{3}$, Mor Nahum ${ }^{4 \dagger}$, Benjamin Brandrett ${ }^{5}$, Michael Reinke ${ }^{6}$, Michael Caldwell ${ }^{7}, K^{2}$ t A. Kiehl ${ }^{8}$ and Sophia Vinogradov ${ }^{2 *}$

1 School of Nursing, University of Maryland Medical Center, Baltimore, MD, United States, ${ }^{2}$ Department of Psychiatry and Behavioral Sciences, University of Minnesota, Minneapolis, MN, United States, ${ }^{3}$ Department of Psychiatry, University of California, San Diego, San Diego, CA, United States, ${ }^{4}$ Posit Science Inc., San Francisco, CA, United States, ${ }^{5}$ Department of Psychiatry, University of California, San Francisco, San Francisco, CA, United States, ${ }^{6}$ Medical School, University of Minnesota, Minneapolis, MN, United States, ${ }^{7}$ Department of Psychology, University of Wisconsin, Madison, WI, United States, ${ }^{8}$ Department of Psychology, University of New Mexico and Mind Research Network, Albuquerque, NM, United States
\end{abstract}

\section{OPEN ACCESS}

Edited by:

Armida Mucci,

University of Campania Luigi

Vanvitelli, Italy

Reviewed by:

Giacomo Deste,

Civil Hospital of Brescia, Italy

Stefano Barlati,

University of Brescia, Italy

${ }^{*}$ Correspondence: Sophia Vinogradov svinogra@umn.edu

${ }^{\dagger}$ Present address: Mor Nahum,

School of Occupational Therapy,

Faculty of Medicine, Hebrew

University, Jerusalem, Israel

Specialty section:

This article was submitted to

Social Psychiatry and

Psychiatric Rehabilitation,

a section of the journal

Frontiers in Psychiatry

Received: 13 January 2020 Accepted: 09 March 2020

Published: 15 April 2020

Citation:

Rowlands A, Fisher M, Mishra J, Nahum M, Brandrett B, Reinke $M$, Caldwell M, Kiehl KA and Vinogradov S (2020) Cognitive

Training for Very High Risk Incarcerated Adolescent Males.

Front. Psychiatry 11:225. doi: 10.3389/fpsyt.2020.00225
Objective: Persistent violent and antisocial behavior, as manifested in conduct disorder (CD) traits, are associated with a range of cognitive deficits. Individuals with more severe cognitive deficits are more likely to commit violent crimes. Currently, no treatments target improving cognition in high-risk CD youth. This pilot study tests the feasibility and efficacy of delivering intensive tablet-based cognitive training (CT) to adolescent males incarcerated in a youth maximum-security prison.

Methods: Participants were fourteen adolescent males, diagnosed with CD. All participants completed up to $30 \mathrm{~h}$ of unsupervised, intensive, adaptive CT exercises that targeted multiple neurocognitive domains, as well as a battery of standardized neurocognitive measures and computerized assessments at baseline and post-training.

Conclusions and Implications for Practice: At baseline, participants exhibited significant impairments on neurocognitive measures, relative to age-matched healthy controls. Twelve participants completed training and showed evidence of target engagement, as indexed by improvement in cognitive processing speed. Significant gains were observed in measures of global cognition, with additional gains in cognitive flexibility at trend level significance. Improvements in these measures were positively related to total training time. In summary, both assessments and intervention appear to be feasible, tolerable, and acceptable in incarcerated youth. Intensive CT shows preliminary efficacy in improving neurocognitive performance in key domains, with large effect sizes, and significant performance improvement associations with the time in training.

Keywords: cognitive remediation, adolescence, conduct disorder, violence, cognition

\section{INTRODUCTION}

Violent criminal behavior carries high personal and societal costs, but only a small proportion of offenders commit the majority of all violent crimes $(1,2)$. These offenders typically display antisocial behavior from a young age-showing "callous-remorseless" traits as well as "impulsive-antisocial" traits that emerge in childhood and adolescence and continue through adulthood $(3,4)$. High levels 
of these callous-unemotional (CU) and conduct-disorder (CD) traits in adolescence are associated with life-course persistent antisocial behavior (5-7). It is now also well-established that persistent violent and antisocial behavior is associated with a range of neurocognitive abnormalities (8-22).

Broadly speaking, the neurocognitive abnormalities seen in persistent violent and antisocial behavior occur in prefrontallymediated higher-order cognitive operations and in socialaffective processing. For example, deficits are seen in sustained attention, working memory, and cognitive control (i.e., impairments in allocation of attentional resources, taskswitching, error-monitoring, response inhibition, decisionmaking, and adaptation to stress), as well as in prefrontal modulatory control over reward processing and emotion processing (23-32). Individuals are noted to spend less time thinking before attempting to solve a problem, which may be indicative of underlying impulsivity (33). Deficits are also seen in processing basic social and emotional cues (such as fear and pain), along with impaired empathy and theory of mind abilities $(14,28,30,33-36)$. Furthermore, it has been proposed that deficits in social information processing are influenced by processes of executive function (37).

Individuals with more severe cognitive deficits show higher CU/CD traits and are more likely to commit violent crimes (15, 16). Cognitive impairment also shows evidence of being associated with recidivism. Impaired executive function appears to predispose to recidivism among young first-time male offenders with $\mathrm{CD}$, and lower scores on the Iowa Gambling Task (indicating lowered prefrontal inhibitory control) predict higher recidivism rates at 6-month follow-up $(17,38)$. Low, relative to high, error-related activity in the anterior cingulate during a Go-NoGo task predicts nearly four times the re-arrest rate within four years in adults (9). In adults, differences in performance (associated with psychopathy or antisocial personality disorder) on decision-making tasks are predictive of higher rates of incarcerations and arrests $(39,40)$.

Taken together, the emerging evidence suggests that developing a treatment to improve cognition-perhaps particularly improvements in inhibitory control and errormonitoring-may in a downstream manner, ameliorate some maladaptive behaviors in high-risk CD youth. Even only modestly improved cognitive capacities, might enable some individuals to make better use of educational and vocational rehabilitation programs, thereby supporting better decisionmaking and more adaptive functioning in the community. It is possible that altering behavior in such a manner could provide further benefit by fostering the development of positive life expectations.

Given the many challenges that researchers face working with ultra-high risk populations, particularly within Department of Justice institutions, it is understandable that a gap in the literature exists. Some focus has been put on the feasibility and efficacy of group psychiatric intervention programs, Cognitive Behavioral Therapy and Mindfulness Training, however these studies do not include children or adolescents and are not specific to a particular psychiatric diagnosis (41-43).
A significant percentage of research done in correctional settings is dedicated to addressing addiction and substance abuse, as well as physiological disorders such as diabetes, Human Immunodeficiency Virus and Hepatitis (44-48). While these studies are extremely valuable in their own right, they fail to directly address another primary cause of recidivism such as violent and antisocial behavior. Correctional settings are increasingly becoming primary settings for psychiatric rehabilitation research, therefore this pilot study offers important preliminary results in support of increased effort and attention from contemporary researchers to further investigate vulnerable populations in such environments.

Recent data suggests that first-time adolescent offenders who subsequently partake in less crime tend to develop improved expectations, and those with higher expectations commit fewer crimes (49). Thus, investigation of cognitive treatments for this population are imperative. To this end, we performed a pilot study of computerized, intensive, targeted cognitive training in 14 adolescent males incarcerated for violent crimes in a youth maximum security prison setting (Mendota Juvenile Treatment Center, MJTC). Our primary goals were: 1) To elucidate the baseline profile of cognitive impairments in a sample of MJTC participants, using both standard neuropsychological measures as well as novel online cognitive assessment tasks; and 2) To determine the feasibility, tolerability, and acceptability of tabletbased intensive cognitive training exercises. Given that this was a pilot study with no control intervention group, our remaining goals were exploratory, and we sought to examine 3) target engagement as a result of training (improvement in speed of processing); 4) the preliminary efficacy of cognitive training; 5) the associations between target engagement, neuropsychological gains, and "dose" of training.

\section{METHODS}

\section{Participants}

\section{Overview of the MJTC Population}

This study took place over an eight-week time period at MJTC. Sixty percent of the youth incarcerated at MJTC have been charged with three or more crimes against persons; $~ 50 \%$ are committed for a violent felony offense, and $~ 50 \%$ have hospitalized or killed a victim. Youth mainly come from economically disadvantaged, violent, or disrupted homes. Fifty percent became involved in crime before their 10th birthday. The gender and racial/ethnic composition is $100 \%$ male, approximately 51\% African American, 38\% Caucasian, 9\% Hispanic, and $2 \%$ Asian or Middle Eastern. The average IQ is 85 , and the mean grade achievement level is $5^{\text {th }}$ grade. Approximately $95 \%$ of MJTC youth have a primary diagnosis of $\mathrm{CD}, 75 \%$ have $\mathrm{ADHD}, 50 \%$ have a concurrent mood disorder, and $5 \%$ have a diagnosis of schizophrenia or bipolar disorder; approximately $70 \%$ have had a substance use disorder. Medication for comorbid disorders was on a case-by-case basis as determined necessary by Mendota treatment staff. Medication 
type or doses were not changed for the purpose of participation in the study.

\section{Pilot Study Participants}

Participants were 14 male adolescents incarcerated at MJTC, ages 13-17 $(\mathrm{Mean}=15.50, \mathrm{SD}=1.40)$, with an average reading grade level of 4.21 ( $\mathrm{SD}=2.46$ ), and average IQ of 79.29 (9.29). Eligibility criteria for study inclusion were a DSM-IV chart diagnosis of CD (diagnosed by MJTC mental health staff upon entry to MJTC), incarceration in the MJTC program for at least 2 months, no active psychosis, and behavioral stability prior to joining the study (not determined to be actively aggressive or behaviorally disruptive by MJTC staff). In addition to a diagnosis of $\mathrm{CD}$, comorbid clinical psychiatric diagnoses included: ADHD $(\mathrm{N}=11)$, Mood Disorders $(\mathrm{N}=9)$, Substance Use Disorders $(\mathrm{N}=6)$, Psychotic Disorders $(\mathrm{N}=1)$, Attachment Disorders $(\mathrm{N}=2)$.

\section{Procedures Enrollment}

Under the on-site supervision of MJTC correctional and mental health treatment staff, referrals were made to the research team. Fourteen MJTC youth were approached over an eight-week time period, met the eligibility criteria, underwent informed consent (as minors, giving assent with patient advocate present), and participated in baseline assessments. Assessments were conducted over two sessions of 45-60 min. Targeted cognitive training via tablets (i.e. iPads) was then offered during 1.5-h time blocks on weekday mornings or afternoons during "down time" when participants were alone in their cells without other obligations or activities. During these cognitive training sessions, a research associate was available to answer questions related to the exercises. At the completion of training, or at the end of the eight-week study period (whichever came first), participants completed post-training assessments.

Participants were paid \$5 per session for assessments, and $\$ 0.50$ an hour for training; payments went to their canteen accounts each time they earned $\$ 2.50$, as per institutional policy. The reward and payment system was approved and compliant with MJTC policies and the MJTC Institutional Review Board.

\section{Cognitive Training}

For the purposes of this pilot study, we aimed to deliver 10-30 h of training of auditory speed of processing, auditory and visual attention, and auditory and visual working memory and cognitive control exercises via tablet [Brain HQ, Posit Science Corporation (PSC)] in the eight-weeks available to us for implementation of the study. Based on our prior cognitive training studies, we have determined that for individuals with diagnosed axis- 1 psychiatric disorders, $30 \mathrm{~h}$ of training is able to produce significant outcomes improvements (50-52). In other studies of targeted cognitive training, especially with respect to intensive training in a singular cognitive training, $\sim 10 \mathrm{~h}$ of training has also demonstrated significant target engagement and cognitive transfer $(53,54)$. Thus, based on the diversity of cognitive training components, $10-30 \mathrm{~h}$ of training has been found to be feasible and efficacious.

The 9 training exercises included in the training suite (see complete list and exercise descriptions in Supplemental Table 1) are tablet versions of the original Brain Fitness Program (BFP) and InSight training suites [see Fisher et al. (50) and Chen et al. (55) for BFP and InSight exercise descriptions]. Over the course of training, exercises are gradually introduced, and collectively emphasize improvement in the learner's speed of processing of basic cognitive abilities through repetitive practice and implicit learning. Exercises require that the learner attend, make fine discriminations, hold in working memory, and perform a response action, to specific components of speech as well as to salient visual-spatial information.

Within a given training session, exercises continuously adjust difficulty level to user performance to maintain an $80 \%$ correct performance rate using adaptive algorithms (56). Correct trials are rewarded with points and animations, whereas incorrect trials are indicated by a "thump" noise as error feedback. At the completion of an exercise, the users are prompted with a screen showing them their score (see Figure 1). In the course of training, exercise configurations gradually become more challenging and difficult. Participants were asked to complete $60 \mathrm{~min}$ of training per session. Each exercise ranged from 2.5 to 4 min in length. At the completion of each training session, training data was securely transferred online to a secure server maintained by PSC.

The tablets used by subjects to complete their training were in a passcode-controlled "Guided Access" mode, which limits the device to a single application, restricts users from exiting the application, and disables areas of the screen that are not relevant to the task in the application. Each user had a unique passwordprotected login that was used for training purposes only.

\section{Assessments}

In order to determine tolerability and acceptability of different methods of neurocognitive assessments in this subject sample, we assessed 7 cognitive domains using well-validated standard paper/pencil and computerized neuropsychological tests, and reassessed 4 of the 7 same domains using a novel on-line computerized cognitive (CC) assessment battery (PSC-CC, Table 1). All raw scores were converted to age-adjusted $\mathrm{T}$ scores using published healthy control normative data for the standard neuropsychological measures. Age-matched, healthy control normative data for the PSC-CC battery was collected from adolescents attending school in the San Francisco Bay area. Parents/legal guardians of these participants provided written informed consent, and adolescents provided verbal assent for this data collection approved by the University of California San Francisco Institutional Review Board. Participants in this control sample were screened to not have any neuropsychiatric disorder and not taking any psychotropic medications at the time of the assessment. Speed of processing and cognition composite scores were computed as the average $\mathrm{T}$-score across speed of processing measures and all standard neuropsychological tests, respectively 

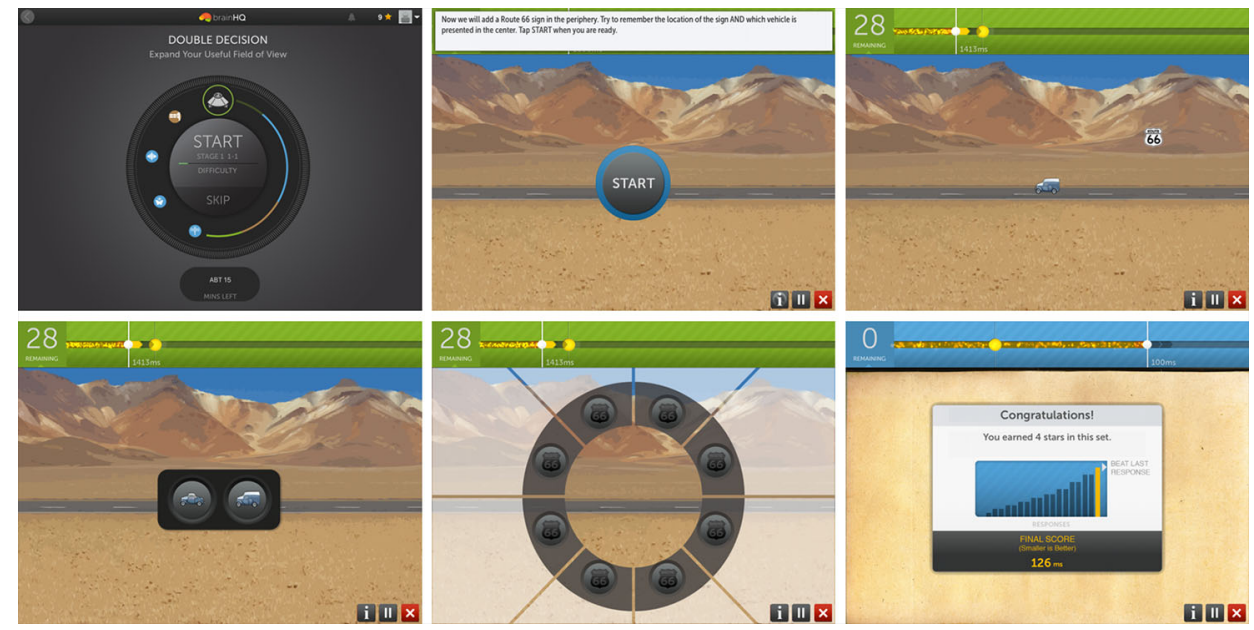

FIGURE 1 | An example of an iPad Brain HQ training exercise, Double Decision. Top row, left to right: Training starts with a "wheel" display of today's training exercises. Then, exercise instructions are displayed. In a Double Decision trial, the user will need to correctly identify the central object (one of two cars) and correctly select the peripheral location of the sign "route 66", as they are quickly flashed on the screen. Bottom row, left to right: response screens (central object followed by peripheral object). At the completion of the exercise, a results screen is displayed, showing the user's score and number of stars earned.

TABLE 1 | Neuropsychological measures and computerized cognitive tests used to assess cognition.

\begin{tabular}{|c|c|c|}
\hline Cognitive Domain & $\begin{array}{c}\text { Standard } \\
\text { Neuropsychological } \\
\text { Measures }\end{array}$ & $\begin{array}{l}\text { Posit Science Inc. } \\
\text { Automated Computerized } \\
\text { Cognitive Tests (PSC-CC) }\end{array}$ \\
\hline Attention & $\begin{array}{l}\text { CogState One-Back } \\
\text { Task (computerized) }\end{array}$ & $\begin{array}{l}\text { A TOVA-like task. Sustained } \\
\text { visual attention task (respond } \\
\text { to visual target, ignore } \\
\text { distractors) }\end{array}$ \\
\hline Speed of Processing & $\begin{array}{l}\text { Trails A, BACS Symbol } \\
\text { Coding, D-KEFS Color, } \\
\text { and Word Reading }\end{array}$ & $\begin{array}{l}\text { Sound Sweeps. An auditory } \\
\text { perceptual processing speed } \\
\text { task (time-order judgment } \\
\text { task for two FM sound } \\
\text { sweeps) }\end{array}$ \\
\hline Working Memory & $\begin{array}{l}\text { UMD Letter Number } \\
\text { Span }\end{array}$ & $\begin{array}{l}\text { A visuospatial working } \\
\text { memory task (remember } \\
\text { spatial location of an array of } \\
\text { objects) }\end{array}$ \\
\hline Verbal Learning & $\begin{array}{l}\text { CogState International } \\
\text { Shopping List Task } \\
\text { (computerized) }\end{array}$ & $\mathrm{N} / \mathrm{A}$ \\
\hline $\begin{array}{l}\text { Cognitive Flexibility/ } \\
\text { Switching }\end{array}$ & Trails B & $\begin{array}{l}\text { A cognitive control task } \\
\text { ("Task Switcher"), in which } \\
\text { the user needs to use a rule } \\
\text { (color vs. shape) to guide } \\
\text { response to the target. The } \\
\text { rule changes each trial }\end{array}$ \\
\hline Problem Solving & NAB Mazes & $\mathrm{N} / \mathrm{A}$ \\
\hline Response Inhibition & $\begin{array}{l}\text { D-KEFS Color Word } \\
\text { Interference }\end{array}$ & $\begin{array}{l}\text { The cognitive control task } \\
\text { described above contains } \\
\text { some elements of response } \\
\text { inhibition (subjects must } \\
\text { inhibit use of rule from prior } \\
\text { trial) }\end{array}$ \\
\hline
\end{tabular}

(see Table 1). Alternate forms of NAB Mazes were administered and counterbalanced at baseline and post-training.

We were provided access to reading and IQ level, which were assessed by MJTC staff upon each participants' entry to MJTC. Reading level was assessed with the Peabody Individual Achievement Test (the standard test used by the Madison, WI School District) and IQ was estimated with the Matrix Reasoning and Vocabulary scales of the Weschler Abbreviated Intelligence Scale.

\section{Analyses}

We performed data analysis on all subjects completing baseline and post-training assessments regardless of hours of intervention. All variables were screened and normally distributed after winsorizing of outlying values $( \pm 2.5 \mathrm{SD}$ from the mean). Paired Samples T-tests were used to test for improvement in cognition from baseline to post-training. Pearson correlations were used to test the association between hours of training and the change in Auditory Processing Speed and the cognition composite scores.

\section{RESULTS}

\section{Feasibility, Tolerability, and Acceptability}

All 14 subjects began training; two dropped out after completing less than $2 \mathrm{~h}$, one due to behavior issues not related to study participation, and one due to discharge from the facility. The exercises were well tolerated and acceptable by the remaining 12 

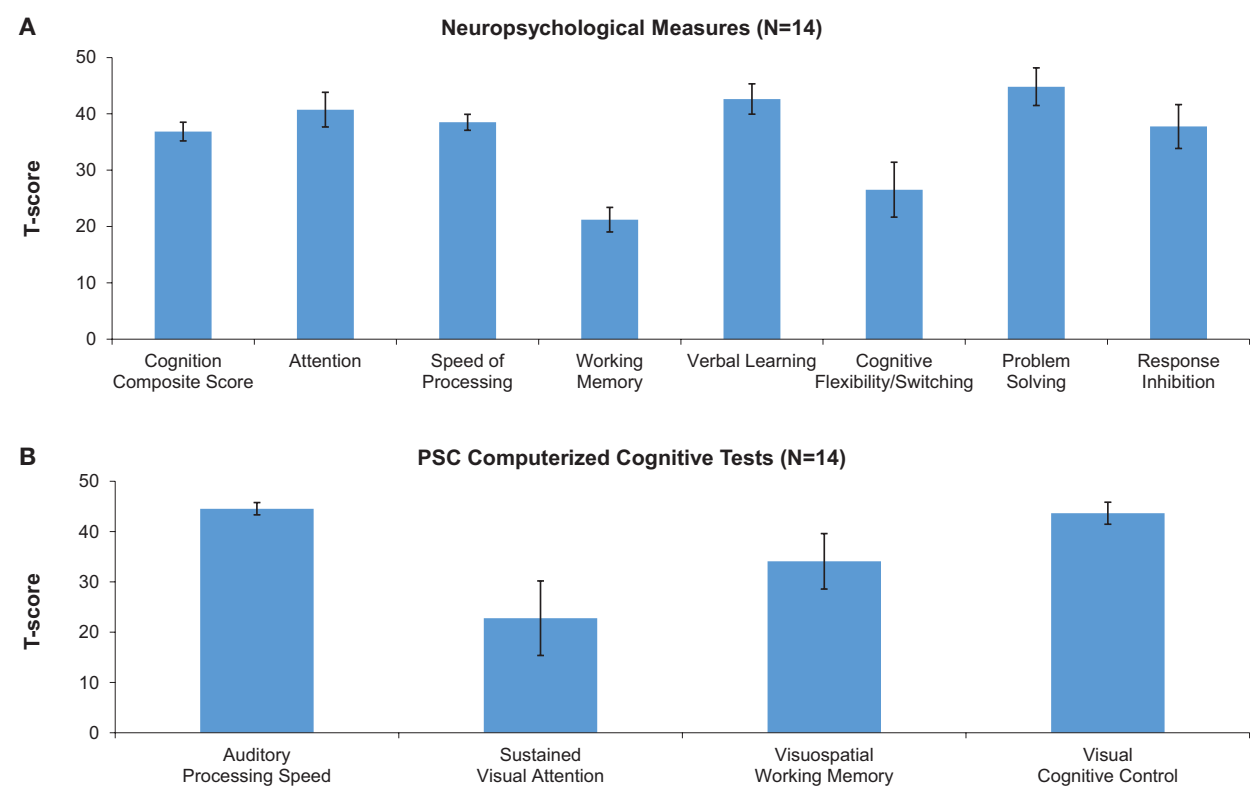

FIGURE 2 | Baseline performance (T-scores) on neuropsychological measures (A) and Posit Science automated computerized cognitive tests (B). A T-score of 50 denotes performance in age-matched healthy controls. * denotes significantly lower performance of incarcerated youth relative to healthy controls.

subjects. Participants were able to tolerate the two assessment sessions of 45-60 min at baseline and post-training including the PSC-CC assessment battery.

Subjects trained 1-5 times per week, for sessions that were an average of $77 \mathrm{~min}$ in length ( $\mathrm{SD}=62.56$, range of $21-210 \mathrm{~min}$ ). Nine boys showed high adherence to the training schedule, training for at least 40 min per week. By the end of the eightweek study period, subjects had trained for a total of $8.1 \mathrm{~h}$ on average ( $\mathrm{SD}=8.31$, range of $1-27$ hours). Subjects were involved in training for $10-30 \mathrm{~h}$ over eight weeks.

\section{Baseline Cognitive Performance}

Compared to age-matched healthy controls, MJTC youth were impaired across a range of measures at baseline, generally performing at least $1 \mathrm{SD}$ below, and in some instances $3 \mathrm{SD}$ below, age-matched norms. Baseline data are shown in Figure 2. The greatest impairments were found on standard neuropsychological measures of working memory and cognitive flexibility/task switching, and on the PSC-CC measures of visual attention and visuospatial working memory.

\section{Evidence of Target Engagement and of Preliminary Efficacy}

We have found in prior studies that gains in auditory processing speed can serve as a behavioral measure of target engagement, i.e. improvements in basic sensory processing speed best correlate with enhancements in more complex cognition $(51,57)$. Consistent with this, we found significant improvement in auditory processing speed as measured by the PSC-CC on-line assessment battery, despite the wide range in training dose achieved during the time period available for the study. This finding indicates that participants were actively engaged with the training exercises. Confirming target

TABLE 2 | Baseline and post-training performance, and effect sizes with lower and upper confidence intervals in neuropsychological measures and automated computerized cognitive tests.

\begin{tabular}{|c|c|c|c|c|c|c|}
\hline $\begin{array}{l}\text { Neuropsychological } \\
\text { Measures }\end{array}$ & $\begin{array}{c}\text { Baseline } \\
\text { Mean } \\
\text { (SD) }\end{array}$ & $\begin{array}{l}\text { Post } \\
\text { Mean } \\
\text { (SD) }\end{array}$ & $\begin{array}{c}\text { T-test } \\
\text { (p value) }\end{array}$ & $\begin{array}{c}\text { Effect } \\
\text { Size } \\
d\end{array}$ & $\begin{array}{l}\text { Lower } \\
\text { C.I. }\end{array}$ & $\begin{array}{l}\text { Upper } \\
\text { C.I. }\end{array}$ \\
\hline $\begin{array}{l}\text { Cognition Composite } \\
\text { Score }\end{array}$ & $\begin{array}{l}36.07 \\
(6.05)\end{array}$ & $\begin{array}{l}41.52 \\
(6.07)\end{array}$ & $\begin{array}{c}3.32 \\
(<0.01)\end{array}$ & 0.90 & -0.01 & 1.74 \\
\hline Attention & $\begin{array}{l}38.86 \\
(9.64)\end{array}$ & $\begin{array}{l}41.10 \\
(8.71)\end{array}$ & $\begin{array}{l}1.00 \\
(0.34)\end{array}$ & 0.24 & -0.60 & 1.07 \\
\hline Speed of Processing & $\begin{array}{l}39.00 \\
(5.13)\end{array}$ & $\begin{array}{l}45.49 \\
(8.14)\end{array}$ & $\begin{array}{c}3.70 \\
(<0.01)\end{array}$ & 0.95 & 0.04 & 1.80 \\
\hline Working Memory & $\begin{array}{l}19.29 \\
(7.87)\end{array}$ & $\begin{array}{l}24.52 \\
(14.31)\end{array}$ & $\begin{array}{c}1.23 \\
(0.25)\end{array}$ & 0.45 & -0.41 & 1.28 \\
\hline Verbal Lea & $\begin{array}{l}40.30 \\
(8.30)\end{array}$ & $\begin{array}{l}43.04 \\
(8.59)\end{array}$ & $\begin{array}{c}1.11 \\
(0.29)\end{array}$ & 0.32 & -0.53 & 1.15 \\
\hline $\begin{array}{l}\text { Cognitive Flexibility/ } \\
\text { Switching }\end{array}$ & $\begin{array}{l}23.81 \\
(20.41)\end{array}$ & $\begin{array}{l}32.33 \\
(19.34)\end{array}$ & $\begin{array}{l}2.05 \\
(0.08)\end{array}$ & 0.43 & -0.43 & 1.26 \\
\hline Problem Solving & $\begin{array}{c}46.06 \\
(13.45)\end{array}$ & $\begin{array}{l}49.83 \\
(9.04)\end{array}$ & $\begin{array}{c}1.60 \\
(0.14)\end{array}$ & 0.33 & -0.52 & 1.16 \\
\hline Response Inhibition & $\begin{array}{c}41.30 \\
(11.73)\end{array}$ & $\begin{array}{c}45.90 \\
(12.94)\end{array}$ & $\begin{array}{l}1.50 \\
(0.17)\end{array}$ & 0.37 & -0.48 & 1.20 \\
\hline \multicolumn{7}{|c|}{ Automated Computerized Cognitive Tests (PSC-CC) } \\
\hline $\begin{array}{l}\text { Auditory Processing } \\
\text { Speed }\end{array}$ & $\begin{array}{l}43.29 \\
(4.04)\end{array}$ & $\begin{array}{l}56.71 \\
(11.34)\end{array}$ & $\begin{array}{l}3.63 \\
(0.01)\end{array}$ & 1.58 & 0.52 & 2.50 \\
\hline $\begin{array}{l}\text { Sustained Visual } \\
\text { Attention }\end{array}$ & $\begin{array}{l}24.07 \\
(25.76)\end{array}$ & $\begin{array}{l}45.67 \\
(12.24)\end{array}$ & $\begin{array}{c}3.84 \\
(0.00)\end{array}$ & 1.07 & 0.09 & 1.96 \\
\hline $\begin{array}{l}\text { Visuospatial Working } \\
\text { Memory }\end{array}$ & $\begin{array}{c}35.75 \\
(19.11)\end{array}$ & $\begin{array}{l}44.84 \\
(8.46)\end{array}$ & $\begin{array}{c}1.86 \\
(0.10)\end{array}$ & 0.62 & -0.31 & 1.48 \\
\hline $\begin{array}{l}\text { Visual Cognitive } \\
\text { Control }\end{array}$ & $\begin{array}{l}41.41 \\
(7.26)\end{array}$ & $\begin{array}{l}52.43 \\
(6.76)\end{array}$ & $\begin{array}{c}3.64 \\
(0.01)\end{array}$ & 1.57 & 0.51 & 2.50 \\
\hline
\end{tabular}



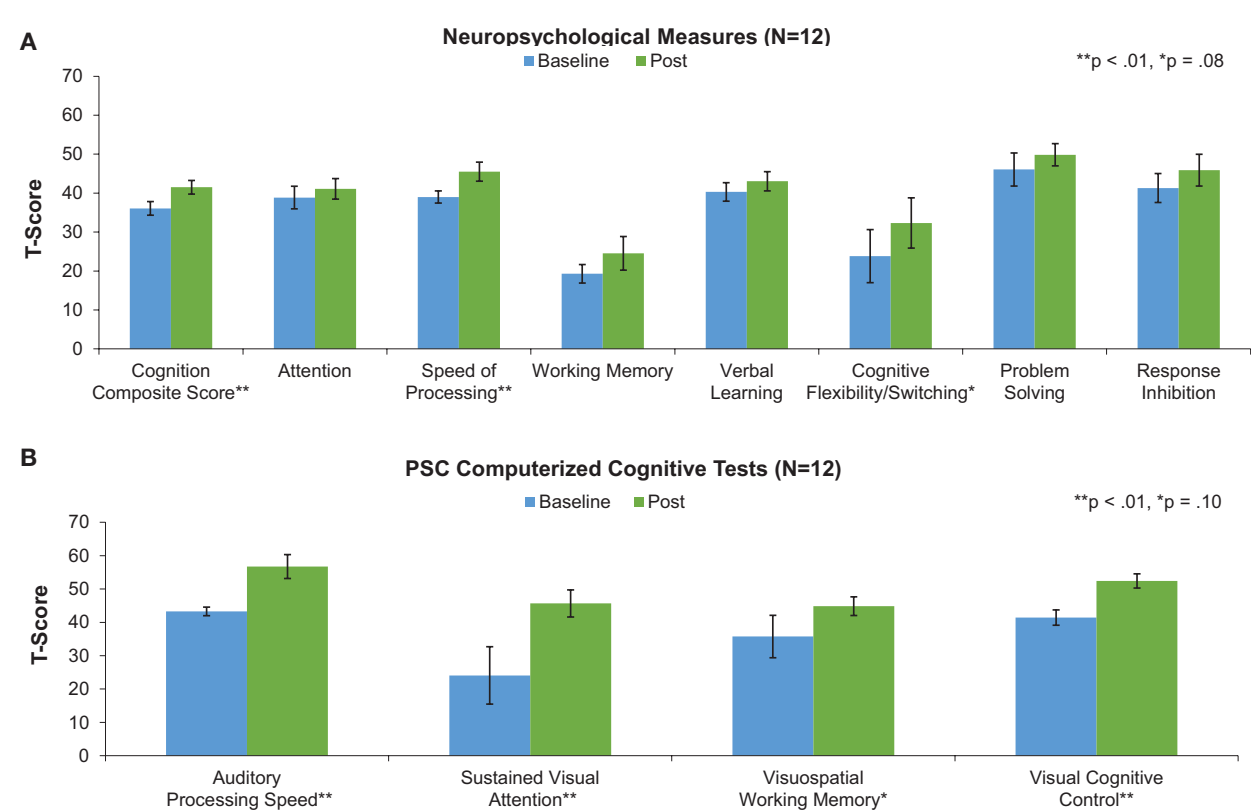

FIGURE 3 | Baseline (blue) and post-training (green) performance on neuropsychological measures (A) and PSC computerized cognitive tests (B) for the 12 participants that completed the study.

engagement, we found significant improvements at the group level in two global neuropsychological outcome measures: the Cognition Composite Score and the general Speed of Processing score. These results indicate generalization of training effects to global cognitive operations. Improvements at trend-level were seen in Cognitive Flexibility/Task Switching, while improvements in measures of Working Memory, Attention, Response Inhibition, and Problem Solving were non-significant (Table 2, Figure 3). Effect sizes were in the large range in the Cognition Composite Score and Speed of Processing Score, and in the small to medium range in Verbal Learning, Working Memory, Cognitive Flexibility/Switching, Problem Solving, and Inhibition (Table 2).

Significant improvement was also seen in the PSC-CC battery measures of sustained visual attention and cognitive control, while improvement in visuospatial working memory was non-significant. Effect sizes were in the large range in 3 of the 4 measures and in the medium range for visuospatial working memory (Table 2).

\section{The Effects of Training "Dose"}

We found strong and significant associations between total training time and improvement in the measure of target engagement, Auditory Processing Speed, the Speed of Processing measure, and the Cognition Composite Score (.61 $<\mathrm{r}<.86, .04<\mathrm{p}<.001$ ) (Figure 4). Improvement in Auditory Processing Speed was also strongly and significantly associated with gains in the neuropsychological Cognition Composite and Speed of Processing measures $(.66<\mathrm{r}<.72, .02<\mathrm{p}<.04)$. These results indicate that the greater the hours of training, the larger was the training-induced target engagement, and the higher the gains made in global neuropsychological outcome measures.

\section{DISCUSSION}

The results of this pilot study indicate first, that both standardized neurocognitive measures and a computerized cognitive assessment battery can be successfully administered to $\mathrm{CD}$ adolescent males incarcerated in a high-security setting for violent crimes. Second, we also found that an intensive course of cognitive training delivered via tablets is feasible and tolerable in this high-risk population. Finally, our results demonstrate preliminary efficacy in improving neurocognitive performance in incarcerated CD youth, and show that cognitive gains induced by training are significantly associated with a psychophysical measure of target engagement and with the "dose" of training. Notably, we found that $86 \%$ percent of the boys who enrolled in the study were able to complete the assessments, adhere to the cognitive training protocol, and provide post-intervention data. This high level of engagement was undoubtedly due to the unique nature of the MJTC treatment setting, with its close collaboration between mental health and correctional staff, as well as the presence and supervision of a psychologist who is engaged in research activities.

The MJTC youth demonstrated a range of comorbid psychiatric diagnoses in addition to CD. They also exhibited a baseline profile of cognitive impairments across a range of measures, including sustained attention, working memory, and 

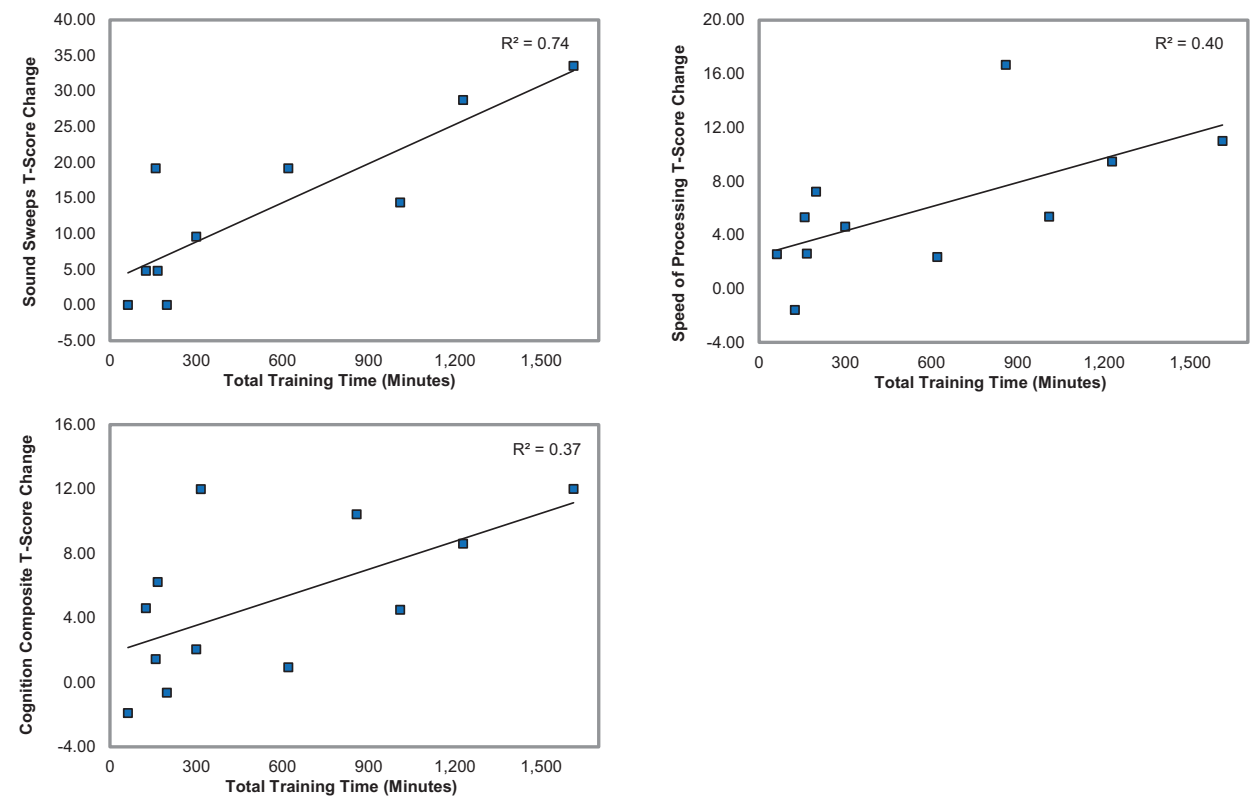

FIGURE 4 | Associations between total training time and the gains in Auditory Processing Speed (Sound Sweeps), Speed of Processing, and the Cognition Composite score.

cognitive flexibility/task switching, with scores ranging $~ 1-3 \mathrm{SD}$ below age-matched norms. Deficits in executive and cognitive control functions involved in problem solving and decision making, such as planning, working memory, inhibition, and cognitive flexibility, have been shown in several studies of CD [for a review, see Matthys et al. (58)]. Our results are also consistent with a study of young individuals with CD, ages 1221 , who had engaged in violent and antisocial behavior (59). The greatest cognitive impairments in Johnson et al., and in our study, were observed in measures of executive function where subjects in both studies performed in the severely impaired range.

Interestingly, we were able to demonstrate that the cognitive impairments in these incarcerated adolescents demonstrated malleability in response to a relatively brief dose of neuroscience-informed cognitive training delivered over a period of eight weeks. The effect sizes suggest that the training may be particularly effective in inducing gains in measures of processing speed, visual attention, visual cognitive control, and global cognition. To a lesser extent, the training shows positive effects in improving working memory, verbal learning, and in other executive functions (i.e. cognitive flexibility, problem solving, and inhibition). Further, the magnitude of the cognitive gains directly associated with the duration of training in which the participants engaged. These findings suggest that gains are not simply a result of practice effects on the neuropsychological tests, of non-specific environmental enrichment due to study participation, or of "placebo effects". However, these results should be interpreted with caution given the small sample size and lack of a control group.
While these preliminary results are encouraging, there are several limitations to this study. First, we studied a small sample of incarcerated youth in a unique treatment setting, as noted above. Second, the lack of a control condition prevents us from determining whether practice effects were an important factor in our results. However, given the large effect sizes observed for the Cognition Composite, Speed of Processing and 3 of 4 computerized cognitive assessments, as well as the strong associations between cognitive improvement, dose of training, and target engagement, it is unlikely that these results are solely due to the effects of repeated exposure to the neuropsychological and computer-based assessments. Third, we do not know if the profile of cognitive impairment we observed in the MJTC youth is due to poor intrinsic motivation or low effort to complete the assessments-though our observations of the participants suggest that this was not the case. It is also important to note that delivering cognitive training in a maximum security setting presents unique challenges, and that future research may best be served by studying these methods in less restrictive environments. Finally, the hours of training that participants completed was variable. Future research is needed to determine what factors contribute to and may enhance compliance. Despite these limitations, our results indicate that cognitive training is feasible, tolerable, and acceptable to incarcerated youth, and that there is evidence of preliminary efficacy. These data provide support for undertaking well-powered double-blind randomized controlled trials of this intervention.

We do not wish to imply that cognitive training should become, or will become, the sole treatment approach for incarcerated high-risk youth. The gold standard will continue 
to be evidence-based psychosocial programs that focus on the mental health and rehabilitative needs of these adolescents. However, if a relatively short course of intensive cognitive training on a mobile device can lead to a modest improvement in certain cognitive domains in high risk incarcerated youthsuch as global cognition and speed of processing-this might enable some individuals to make better use of educational and vocational rehabilitation programs, thereby supporting better decision-making and more adaptive functioning upon release into the community.

\section{DATA AVAILABILITY STATEMENT}

The datasets generated for this study are available on request to the corresponding author.

\section{ETHICS STATEMENT}

This study was approved by the Institutional Review Boards at Medota Juvenille Treatment Center and the University of California San Francisco. Participants provided assent, and a

\section{REFERENCES}

1. Hodgins S. Status at age 30 of children with conduct problems. Stud Crime Crime Prev (1994) 3:41-62.

2. Moffitt TE. Adolescence-limited and life-course-persistent antisocial behavior: a developmental taxonomy. psychol Rev (1993) 100(4):674-701. doi: 10.1037/0033-295X.100.4.674

3. Cauffman E, Kimonis ER, Dmitrieva J, Monahan KC. A multimethod assessment of juvenile psychopathy: Comparing the predictive utility of the PCL:YV, YPI, and NEO PRI. psychol Assess (2009) 21(4):528-42. doi: 10.1037/a0017367

4. Blair RJR. The amygdala and ventromedial prefrontal cortex in morality and psychopathy. Trends Cogn Sci (2007) 11(9):387-92. doi: 10.1016/j.tics.2007.07.003

5. Frick PJ, White SF. Research review: The importance of callous-unemotional traits for developmental models of aggressive and antisocial behavior. J Child Psychol Psychiatry (2008) 49(4):359-75. doi: 10.1111/j.1469-7610.2007.01862

6. Blair RJR. Neurobiological basis of psychopathy. Br J Psychiatry (2003) 182 (1):5-7. doi: 10.1192/bjp.182.1.5

7. Frick P, Marsee M. Psychopathy and developmental pathways to antisocial behavior in youth. In: Patrick C, editor. Handbook of Psychopathy. New York City, NY, U.S: Guilford Press (2005). p. 353-74.

8. Pujara M, Motzkin JC, Newman JP, Kiehl KA, Koenigs M. Neural correlates of reward and loss sensitivity in psychopathy. Soc Cogn Affect Neurosci (2014) 9(6):794-801. doi: 10.1093/scan/nst054

9. Aharoni E, Vincent GM, Harenski CL, Calhoun VD, Sinnott-Armstrong W, Gazzaniga MS, et al. Neuroprediction of future rearrest. Proc Natl Acad Sci (2013) 110(15):6223-8. doi: 10.1073/pnas.1219302110

10. Decety J, Skelly L, Yoder KJ, Kiehl KA. Neural processing of dynamic emotional facial expressions in psychopaths. Soc Neurosci (2014) 9(1):3649. doi: 10.1080/17470919.2013.866905

11. Blair RJR. The neurobiology of psychopathic traits in youths. Nat Rev Neurosci (2013) 14(11):786-99. doi: 10.1038/nrn3577

12. Morgan AB, Lilienfeld SO. A meta-analytic review of the relation between antisocial behavior and neuropsychological measures of executive function. Clin Psychol Rev (2000) 20(1):113-36. doi: 10.1016/S0272-7358(98)00096-8

13. Jones AP, Laurens KR, Herba CM, Barker GJ, Viding E. Amygdala hypoactivity to fearful faces in boys with conduct problems and callous- legally-authorized-representative (LAR) provided adult guardian consent.

\section{AUTHOR CONTRIBUTIONS}

All authors conceived the presented idea, discussed the results and contributed to the final manuscript. $\mathrm{AR}, \mathrm{BB}$, and $\mathrm{MC}$ carried out the experiment. MF and JM performed computations and verified analytical methods.

\section{FUNDING}

Funds for this pilot study were provided to Dr. Vinogradov by the Northern California Institute of Research and Education.

\section{SUPPLEMENTARY MATERIAL}

The Supplementary Material for this article can be found online at: https://www.frontiersin.org/articles/10.3389/fpsyt.2020. 00225/full\#supplementary-material

unemotional traits. Am J Psychiatry (2009) 166(1):95-102. doi: 10.1176/ appi.ajp.2008.07071050

14. Dadds MR, Perry Y, Hawes DJ, Merz S. Attention to the eyes and fearrecognition deficits in child psychopathy. Br J Psychiatry (2006) 189(3):280-1. doi: 10.1192/bjp.bp.105.018150

15. May JS, Beaver KM. The neuropsychological contributors to psychopathic personality traits in adolescence. Int J Offender Ther Comp Criminol (2014) 58 (3):265-85. doi: 10.1177/0306624X12469861

16. Beaver KM, Vaughn MG, DeLisi M, Barnes JC, Boutwell BB. The neuropsychological underpinnings to psychopathic personality traits in a nationally representative and longitudinal sample. Psychiatr Q (2012) 83 (2):145-59. doi: 10.1007/s11126-011-9190-2

17. Beszterczey S, Nestor PG, Shirai A, Harding S. Neuropsychology of decision making and psychopathy in high-risk ex-offenders. Neuropsychology (2013) 27(4):491-7. doi: 10.1037/a0033162

18. Cope LM, Ermer E, Nyalakanti PK, Calhoun VD, Kiehl KA. Paralimbic gray matter reductions in incarcerated adolescent females with psychopathic traits. J Abnormal Child Psychol (2014) 42(4):659-68. doi: 10.1007/s10802-0139810-4

19. Hooker CI, Bruce L, Fisher M, Verosky SC, Miyakawa A, D’Esposito M, et al. The influence of combined cognitive plus social-cognitive training on amygdala response during face emotion recognition in schizophrenia. Psychiatry Res (2013) 213(2):99-107. doi: 10.1016/j.pscychresns.2014.04.001

20. Steele VR, Aharoni E, Munro GE, Calhoun VD, Nyalakanti P, Stevens MC, et al. A large scale $(\mathrm{N}=102)$ functional neuroimaging study of response inhibition in a Go/NoGo task. Behav Brain Res (2013) 256:529-36. doi: 10.1016/j.bbr.2013.06.001

21. Thijssen S, Kiehl A. Functional connectivity in incarcerated male adolescents with psychopathic traits. Psychiatry Res: Neuroimaging (2017) 30(265):35-44. doi: 10.1016/j.pscychresns.2017.05.005

22. Fehlbaum LV, Raschle NM, Menks WM, Prätzlich M, Flemming E, Wyss L, et al. Altered neuronal responses during an affective stroop task in adolescents with conduct disorder. Front Psychol (2018) 9:1961. doi: 10.3389/fpsyg.2018.01961

23. Alegria AA, Radua J, Rubia K. Meta-analysis of fMRI studies of disruptive behavior disorders. Am J Psychiatry (2016) 173(11):1119-30. doi: 10.1176/ appi.apj.2016.15081089 
24. Aghajani M, Klapwijk ET, van der Wee NJ, Rombourts SARB, Boon AE, van Beelen $\mathrm{P}$, et al. Disorganized amygdala networks in conduct-disordered juvenile offenders with callous-unemotional traits. Biol Psychiatry (2017) 82 (4):283-93. doi: 10.1016/j.biopsych.2016.05.017

25. Veroude K, von Rhein D, Chauvin RJ, Mennes MJ, Franke B, Heslenfeld DJ, et al. The link between callous-unemotional traits and neural mechanisms of reward processing: An fMRI study. Psychiatry Res: Neuorimag (2016) 255:7580. doi: 10.1016/j.pscychresns.2016.08.005

26. Yang Y, Raine A, Joshi AA, Joshi S, Chang YT, Schug RA, et al. Frontal information flow and connectivity in psychopathy. Br J Psychiatry: J Ment Sci (2012) 201(5):408-9. doi: 10.1192/bjp.bp.111.107128

27. Ogilvie JM, Stewart AL, Chan RCK, Shum DHK. Neuropsychological measures of executive function and antisocial behavior: A meta-analysis. Criminology (2011) 49(4):1063-107. doi: 10.1111/j.1745-9125.2011.00252.x

28. Dodge KA, Schwartz D. Social information processing mechanisms in aggressive behavior. In: Stoff DM, Breiling J, Maser JD, editors. Handbook of antisocial behavior. Hoboken, NJ, US: John Wiley \& Sons Inc. (1997). p. 171-80.

29. Buckholtz JW, Treadway MT, Cowan RL, Woodward ND, Bennings SD, Li R, et al. Mesolimbic dopamine reward system hypersensitivity in individuals with psychopathic traits. Nat Neurosci (2010) 13(4):419-21. doi: 10.1038/nn2510

30. Dodge KA. Social-cognitive mechanisms in the development of conduct disorder and depression. Annu Rev Psychol (1993) 44:559-84. doi: 10.1146/ annurev.ps.44.020193.003015

31. Hosking JG, Kastman EK, Dorfman HM, Samanez-Larkin GR, BaskinSommers A, Kiehl KA, et al. Disrupted prefrontal regulation of striatal subjective value signals in psychopathy. Neuron (2017) 95(1):221-31. doi: 10.1016/j.neuron.2017.06.030

32. Schoorl J, van Rijn S, de Wied M, van Goozen S, Swaab H. Boys with oppositional defiant disorder show impaired adaptation during stress: An executive functioning study. Child Psychiatry Hum Dev (2018) 49(2):298-307. doi: 10.1007/s10578-017-0749-5

33. Delfin C, Andiné P, Hofvander B, Billstedt E, Wallinius M. Examining associations between psychopathic traits and executive functions in incarcerated violent offenders. Front Psychiatry (2018) 9:310. doi: 10.3389/fpsyt.2018.00310

34. Orobio de Castro B, Veerman JW, Koops W, Bosch JD, Monshouwer HJ. Hostile attribution of intent and aggressive behavior: a meta-analysis. Child Dev (2002) 73(3):916-34. doi: 10.1111/1467-8624.00447

35. Drayton LA, Santos LR, Baskin-Sommers A. Psychopaths fail to automatically take the perspective of others. Proc Natl Acad Sci U States America (2018) 115 (13):3302-7. doi: 10.1073/pnas

36. Baker RH, Clanton RL, Rogers JC, De Brito SA. Neuroimaging findings in disruptive behavior disorders. CNS Spectr (2015) 20(4):369-81. doi: 10.1017/ S1092852914000789

37. Van Nieuwenhuijzen M, Van Rest MM, Embregts PJ, Vriens A, Oostermeijer S, Van Bokhoven I, et al. Executive functions and social information processing in adolescents with severe behavior problems. Child Neuropsychol (2017) 23(2):22841. doi: 10.1080/09297049.2015.1108396

38. Miura H, Fuchigami Y. Impaired executive function in 14- to 16-year-old boys with conduct disorder is related to recidivism: A prospective longitudinal study. Crim Behav Ment Health (2017) 27(2):136-45. doi: 10.1002/cbm.1993

39. Baskin-Sommers A, Stuppy-Sullivan AM, Buckholtz JW. Psychopathic individuals exhibit but do not avoid regret during counterfactual decision making. Proc Natl Acad Sci U States A (2016) 113(50):14438-43. doi: 10.1073/pnas.1609985113

40. Buckholtz JW, Karmarkar U, Ye S, Brennan GM, Baskin-Sommers A. Blunted ambiguity aversion during cost-benefit decisions in antisocial individuals. Sci Rep (2017) 7(1):2030. doi: 10.10384/s41598-017-02149-6

41. Leidenfrost CA, Schoelerman RM, Maher M, Antonius D. The development and efficacy of a group intervention program for individuals with serious mental illness in jail. Int J Law Psychiatry (2017) 54:98-106. doi: 10.10.1016/j.ijlp.2017.06.004

42. Umbach R, Raine A, Leonard NR. Cognitive decline as a result of incarceration and the effects of a CBT/MT intervention: A cluster-randomized controlled trial. Crim Justice Behav (2018) 45(1):31-55. doi: 10.1177/0093854817736345

43. Al-Rousan T, Rubenstein L, Sieleni B, Deol H, Wallace RB. Inside the nation's largest mental health institution: A prevalence study in a state prison system. BMC Public Health (2017) 17:342. doi: 10.1186/s12889-017-4257-0

44. Fink BC, Steele VR, Maurer MJ, Fede S, Calhoun VD, Kiehl K. Brain potentials predict substance abuse treatment completion in a prison sample. Brain Behav (2016) 6(8):e00501. doi: 10.1002/brb3.501
45. Spaulding AC, Anderson EJ, Khan MA, Taborda-Vidarte CA, Phillips JA. HIV and HCV in U.S. Prisons and Jails: The correctional facility as a bellwether over time for the community's infections. AIDS Rev (2017) 19:134-47. doi: 10.24875/AIDSRev.M17000006

46. Fine A, Gallaway MS, Dukate A. Prevention in prison: the diabetes prevention program in a correctional setting. Diabetes Spectr (2019) 32(4):331-7. doi: $10.2337 / \mathrm{ds} 18-0080$

47. Kassar K, Roe C, Desimone M. Use of telemedicine for management of diabetes in correctional facilities. Telemed e-Health (2017) 23(1):55-9. doi: $10.1089 /$ tmj.2016.0036

48. Lafferty L, Rance J, Grebely J, Lloyd AR, Dore GJ, Treloar C. Understanding facilitators and barriers of direct-acting antiviral therapy for hepatitis $\mathrm{C}$ virus infection in prison. J Viral Hepat (2018) 25(12):1526-32. doi: 10.1111/jvh.12987

49. Mahler A, Fine A, Frick PJ, Steinberg L, Cauffman E. Expecting the unexpected? Expectations for future success among adolescent first-time offenders. Child Dev (2018) 89(6):535-51. doi: 10.1111/cdev.12977

50. Fisher M, Holland C, Merzenich MM, Vinogradov S. Using neuroplasticitybased auditory training to improve verbal memory in schizophrenia. Am J Psychiatry (2009) 166(7):805-11. doi: 10.1176/appi.ajp.2009.08050757

51. Fisher M, Loewy R, Carter C, Lee A, Ragland JD, Niendam T, et al. Neuroplasticity-based auditory training via laptop computer improves cognition in young individuals with recent onset schizophrenia. Schizophr Bull (2015) 41(1):250-8. doi: 10.1093/schbul/sbt232

52. Mishra J, Sagar R, Joseph AA, Gazzaley A, Merzenich MM. Training sensory signal-to-noise resolution in children with ADHD in a global mental health setting. Trans Psychiatry (2016) 6:e781. doi: 10.1038/tp.2016.45

53. Anguera JA, Boccanfuso J, Rintoul JL, Al-Hashimi O, Faraji F, Janowich J, et al. Video game training enhances cognitive control in older adults. Nature (2013) 501(7465):97-101. doi: 10.1038/nature12486

54. Mishra J, de Villers-Sidani E, Merzenich M, Gazzaley A. Adaptive training diminishes distractibility in aging across species. Neuron (2014) 84(5):1091103. doi: 10.1016/j.neuron.2014.10.034

55. Chen CX, Mao RH, Li SX, Zhao YN, Zhang M. Effect of visual training on cognitive function in stroke patients. Int J Nurs Sci (2015) 2(4):329-33. doi: 10.1016/j.ijnss.2015.11.002

56. Levitt H. Transformed up-down methods in psychoacoustics. J Acoust Soc America (1971) 49(2):476-7. doi: 10.1121/1.1912374

57. Biagianti B, Fisher M, Neilands TB, Loewy R, Vinogradov S. Engagement with the auditory processing system during targeted auditory cognitive training mediates changes in cognitive outcomes in individuals with schizophrenia. Neuropsychology (2016) 30(8):998-1008. doi: 10.1037/neu0000311

58. Matthys W, Vanderschuren LJ, Schutter DJ, Lochman JE. Impaired neurocognitive functions affect social learning processes in oppositional defiant disorder and conduct disorder: Implications for interventions. Clin Child Family Psychol Rev (2012) 15(3):234-46. doi: 10.1007/s10567-012-0118-7

59. Johnson VA, Kemp AH, Heard R, Lennings CJ, Hickie IB. Childhood- versus adolescent-onset antisocial youth with conduct disorder: Psychiatric illness, neuropsychological and psychosocial function. PloS One (2015) 10(4): e0121627. doi: 10.1371/journal.pone.0121627

Conflict of Interest: The cognitive training software used in this study was supplied to the corresponding author free of charge by Posit Science. SV serves on Scientific Advisory Boards for the following organizations: Mindstrong, Inc, Alkermes, Inc., and Psyberguide. SV and MF have scientific collaborations with scientists at Post Science, Inc. MN is the co-inventor of the cognitive training software used in the study. She was a paid employee at Posit Science during the study and is now a paid consultant to Posit Science.

The remaining authors declare that the research was conducted in the absence of any commercial or financial relationships that could be construed as a potential conflict of interest.

Copyright (C) 2020 Rowlands, Fisher, Mishra, Nahum, Brandrett, Reinke, Caldwell, Kiehl and Vinogradov. This is an open-access article distributed under the terms of the Creative Commons Attribution License (CC BY). The use, distribution or reproduction in other forums is permitted, provided the original author(s) and the copyright owner(s) are credited and that the original publication in this journal is cited, in accordance with accepted academic practice. No use, distribution or reproduction is permitted which does not comply with these terms. 